09

\title{
Определение толщин в карбидкремниевых структурах методом частотного анализа спектра отражения
}

\author{
() М.Ф. Панов, М.В. Павлова \\ Санкт-Петербургский государственный электротехнический университет „ЛЭТИ“, \\ 197376 Санкт-Петербург, Россия \\ e-mail: 19_panov_59@mail.ru
}

Поступило в Редакцию 22 сентября 2020 г.

В окончательной редакции 3 декабря 2020 г.

Принято к публикации 7 декабря 2020 г.

Разработана методика определения толщин после получения одно- и многослойных карбидкремниевых структур методом частотного анализа спектра инфракрасного отражения, на форму которого влияет спектральная интерференция в слоях и группах слоев. Анализ спектра выполнен в программном пакете LabView. Представлены результаты, полученные как для модельных структур, расчетный спектр отражения которых определялся с использованием диэлектрической функции, учитывавшей реакцию колебаний решетки и свободных носителей заряда, так и для экспериментальных спектров реальных многослойных структур приборов силовой электроники.

Ключевые слова: слой, отражение, интерференция, спектр.

DOI: $10.21883 /$ JTF.2021.05.50696.276-20

\section{Введение}

Карбид кремния является важнейшим из материалов современной электроники как характеризующийся экстремальными характеристиками по теплопроводности, критической напряженности электрического поля, дрейфовой скорости носителей заряда, устойчивости к воздействию высоких температур, химически агрессивных сред и радиации $[1,2]$. В технологическом цикле создания приборов на основе карбида кремния одной из главных является операция постростовой диагностики прозрачных в инфракрасной (ИК) области эпитаксиальных $\mathrm{SiC}-$-композиций на карбидкремниевой подложке, где важнейшими из параметров являются толщины приборных структур. Целью настоящей работы явилось одновременное определение толщин нескольких технологических слоев готовой эпитаксиальной приборной структуры.

Наибольшей оперативностью среди группы известных способов контроля слоев характеризуются неразрушающие бесконтактные методы, а среди которых важнейшим является метод анализа ИК спектра. Работы [3-5] посвящены исследованиям эпитаксиальных $\mathrm{SiC}-$ слоев путем одновременного определения толщины и физических параметров материала слоя, таких, как концентрация и подвижность носителей. В работе [6] при аппроксимации спектра дополнительно оценивалась шероховатость межслойных границ. Для этого выполнялась аппроксимация экспериментального спектра теоретической зависимостью с несколькими дополнительными подгоночными параметрами, характеризующими диэлектрическую функцию материала SiC. В связи с большим количеством одновременно определяемых параметров и сложностью формулирования критериев подгонки спектров данный метод контроля толщины не представляется достаточно надежным и оперативным.

В настоящей работе применен метод частотного анализа ИК спектров отражения, который ориентирован на исследование зависимости формы спектральной кривой, прежде всего, от набора толщин системы слоев и их взаимного расположения. Примененная методика не ограничена числом слоев и позволяет получить численные значения толщин, используя результаты измерений, выполняемые на стандартном фурье-спектрометре.

Методика основана на анализе кривой, получаемой в результате спектральной интерференции и представляющей собой наложение синусоид, период каждой из которых связан с толщиной отдельного слоя исследуемой структуры. Фурье-анализ такого наложения, выполненный нами в программном пакете LabView, позволил определить частоты спектра отражения и пропорциональные им толщины слоев.

\section{1. Эксперимент}

Характерный вид спектра отражения карбидкремниевых структур для различных толщин, типов и уровней легирования эпитаксиальных слоев представлен на рис. 1. Форма кривых определяется физическими параметрами материалов подложки и слоев, а также толщинами и легированием слоев. Характерной особенностью спектра отражения материала $\mathrm{SiC}$ в ближнем и среднем ИК диапазоне (вблизи $1000 \mathrm{~cm}^{-1}$ ) является наличие области однофононного взаимодействия фотонов с фононами решетки (область однофононного резонанса или остаточных лучей) [7,8]. Этот участок спектра в связи с поглощением на фононах характери- 


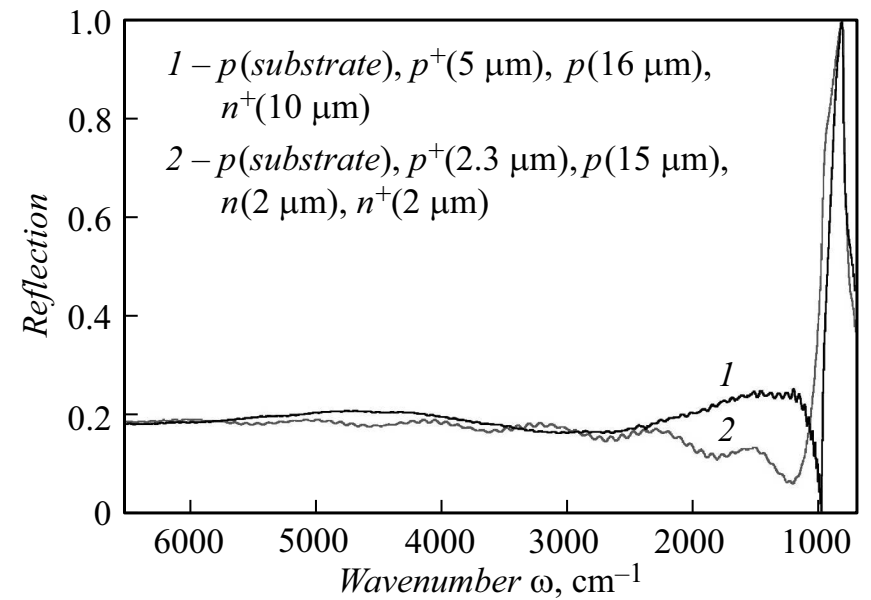

Рис. 1. Экспериментальные спектры отражения многослойных карбидкремниевых структур с различными параметрами слоев.

зуется аномальной дисперсией и сильной зависимостью показателя преломления от частоты. Более высокочастотная область $\left(1500-6500 \mathrm{~cm}^{-1}\right)$ соответствует весьма малой дисперсии показателя преломления $\mathrm{SiC}$ [9]. Она и используется для определения толщин слоев структуры.

Форма кривой во всем приведенном диапазоне частот находится под влиянием спектральной интерференции в слоях отражающей структуры. Этими слоями являются технологические эпитаксиальные, а могут быть, например, тонкие поверхностные нарушенные слои с очень большим периодом интерференции (она заметна у кривой 1 на рис. 1). В рамках приведенного спектрального диапазона имеет место уменьшение амплитуды интерференции с ростом частоты, что связывается с некоторым ростом поглощения на примеси азота изза возможности перехода электронов в более высокие энергетические состояния.

Для спектрального анализа кривой отражения используется участок с малой дисперсией $\left(\omega>1500 \mathrm{~cm}^{-1}\right)$. В случае однослойной структуры данный участок спектра промодулирован отчетливо выраженной синусоидой [10]. При этом толщину слоя легко рассчитать по визуально измеренному периоду интерференции $\Delta \omega$ с помощью простой формулы, которая при нормальном падении волны на поверхность и в предположении постоянства показателя преломления $(n(\omega)=$ const $)$ имеет вид [11]

$$
d=(2 \Delta \omega n)^{-1}
$$

где $\Delta \omega-$ период интерференционных спектральных колебаний, а численное значение показателя преломления $n$ для $\mathrm{SiC}$ политипа $4 \mathrm{H}$ в используемом диапазоне ИК спектра составляет приблизительно 2.64 [9].

\section{2. Расчет}

В случае усложнения структуры хотя бы до двухслойной визуальное определение двух периодов интерференции может оказаться уже невозможным. В качестве подтверждения можно привести наложение двух синусоидальных колебаний с периодами в 64 и 512 произвольные единицы (далекие периоды, рис. 2,a) и 64 и 57 произвольные единицы (близкие периоды, рис. 2, $b$ ), где визуально наблюдается одинаковый период низкочастотных „биений“. Таким образом, правильное определение частотных составляющих спектра невозможно без частотного анализа спектра отражения. В настоящей работе оно выполнено с помощью фурье-преобразования в программном пакете LabView.

Из рассмотрения исключается наиболее низкочастотная составляющая спектра, возникающая из формы самого спектра отражения материала $\mathrm{SiC}$.

На рис. 3 представлена расчетная зависимость спектра отражения двухслойной карбидкремниевой структуры со слоями толщиной 25 и $6 \mu \mathrm{m}$ (использованные концентрации носителей заряда приведены на правой вставке). При построении теоретического спектра отражения использована диэлектрическая функция (частотная зависимость диэлектрической проницаемости), в которой аддитивно учитываются реакции колебаний решетки (однофононное взаимодействие) и свободных носителей заряда (плазмонный резонанс) [12,13]. Слабо меняющая спектральная компонента отражения (называемая линией тренда) показана для участка спектра на верхней левой вставке рис. 3. Результат спектрального анализа, полученный после вычисления линии тренда и ее программного выравнивания, приведен на нижней левой вставке рис. 3. Как следует из формулы (1),
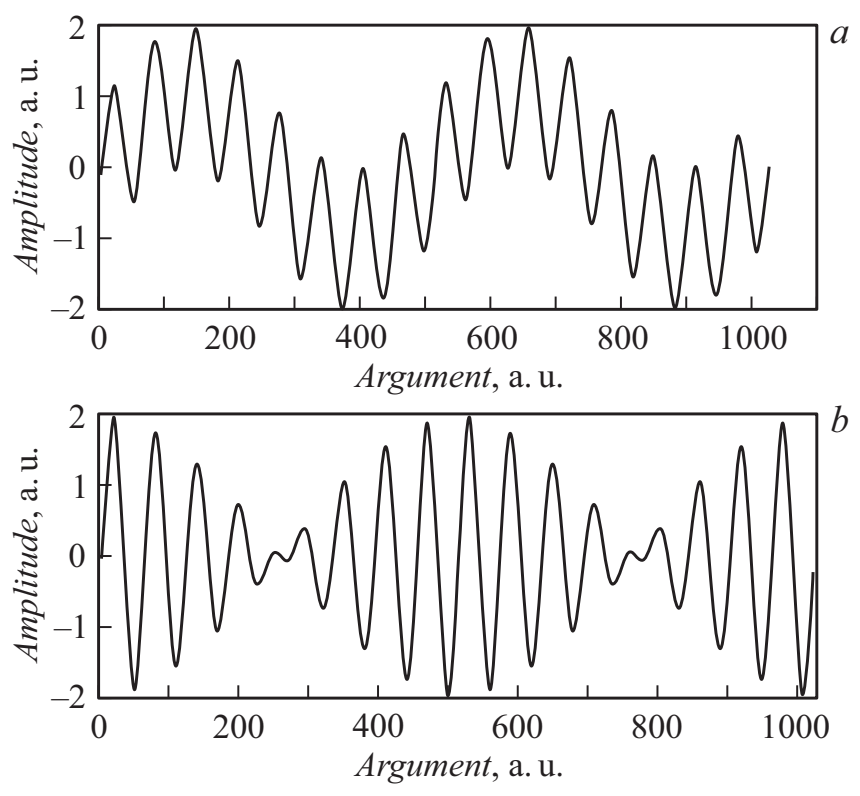

Рис. 2. Суперпозиция двух синусоид с далекими (a) и близкими $(b)$ периодами. 


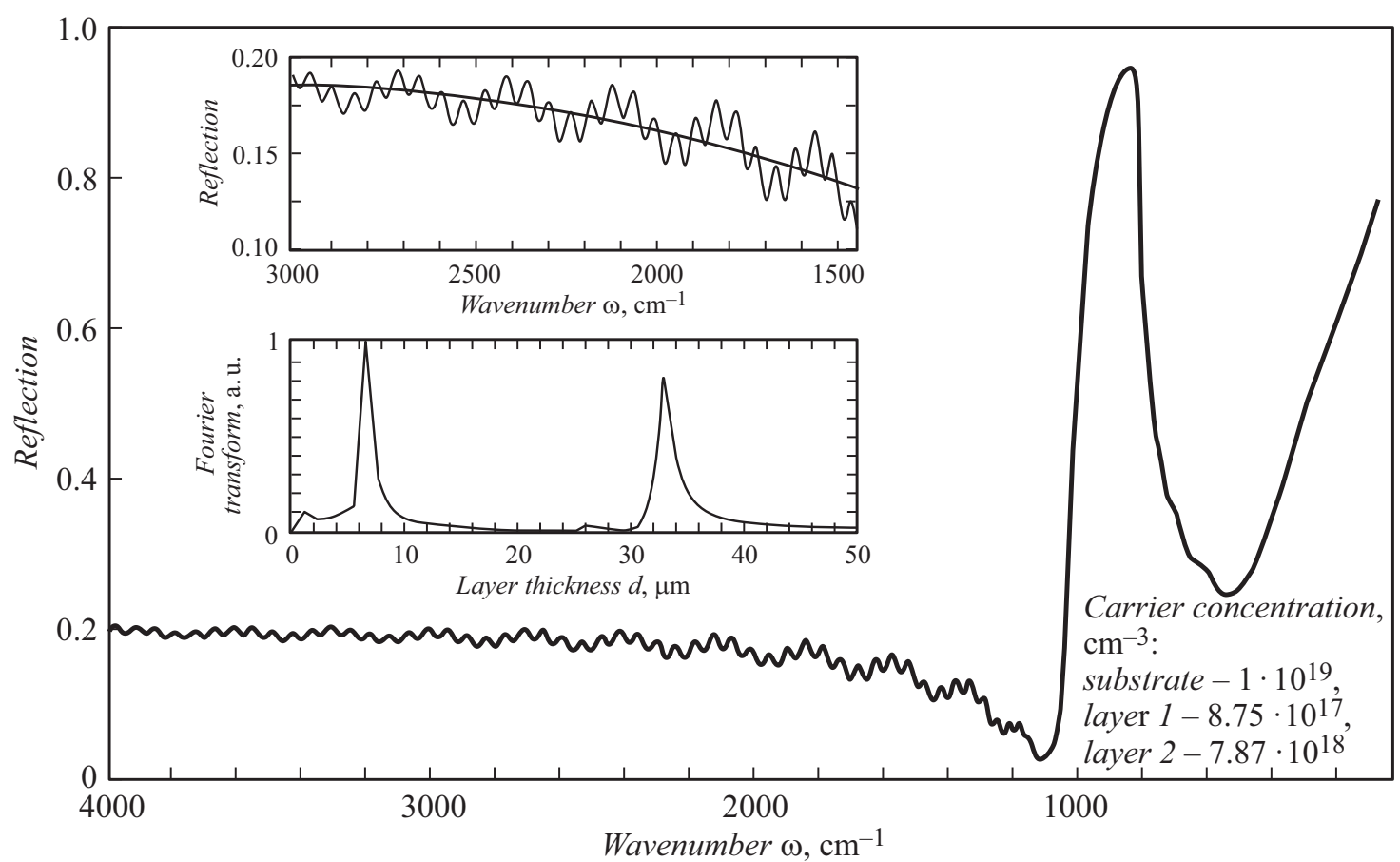

Рис. 3. Расчетный спектр отражения двухслойной карбидкремниевой структуры, линия тренда и результат обработки с помощью фурье-преобразования.

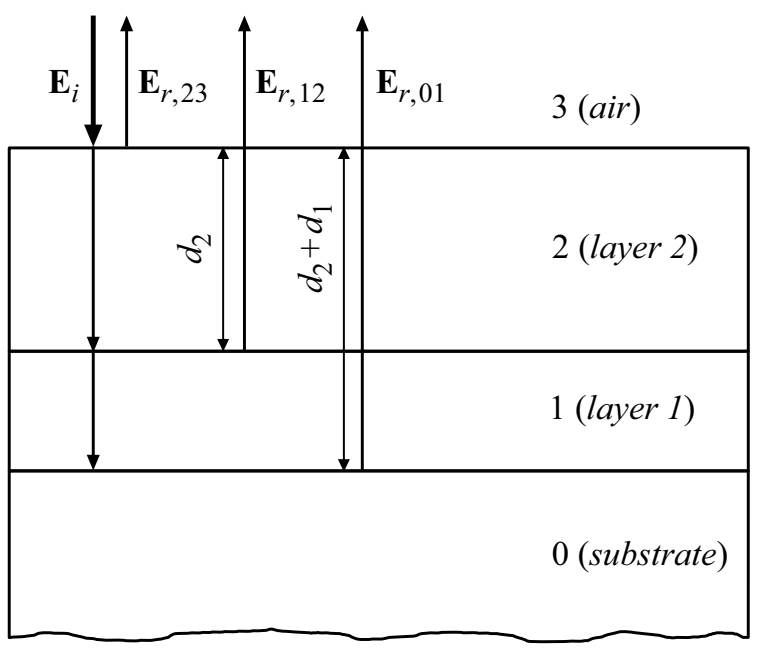

Рис. 4. Образование компонент спектра отражения двухслойной структуры.

толщина обратно пропорциональна периоду и прямо пропорциональна частоте осцилляций спектра отражения. Поэтому результат фурье-преобразования отградуирован непосредственно в значениях толщины.

Следует отметить, что среди частотных компонент спектра отражения (расчетного и экспериментального) двухслойной структуры в результате фурье-анализа получаются компоненты, соответствующие толщине верхнего слоя и суммарной толщине обоих слоев (рис. 3). Объясняется это следующим образом. Наблюдаемая в эксперименте интерференция когерентных волн, отраженных от оптических границ, имеет место над поверхностью верхнего слоя. Разность хода, являющаяся фактором возникновения спектральных колебаний коэффициента отражения, определяется расстоянием между верхней границей структуры и конкретной отражающей внутренней границей. Поэтому в случае двухслойной структуры, схематически представленной на рис. 4, в спектре отражения проявляются компоненты, соответствующие толщинам $d_{2}$ и $d_{2}+d_{1}$ (как результат интерференции отраженной от верхней поверхности волны $\mathbf{E}_{r, 23}$ и отраженных от внутренних границ волн $\mathbf{E}_{r, 12}$ и $\left.\mathbf{E}_{r, 01}\right)$. Данная закономерность всякий раз проявлялась и при анализе спектров отражения структур с количеством слоев, большим одного.

\section{3. Результаты и обсуждение}

Экспериментальные спектры отражения многослойных эпитаксиальных карбидокремниевых структур (политипа 4Н), предназначенных для создания приборов силовой электроники, получены на ИК фурьеспектрометре Nikolet-6700 с разрешением $4 \mathrm{~cm}^{-1}$ и представлены в спектральной области нормальной дисперсии на рис. 5. Кривые $a-c$ определены для трехслойных структур, параметры которых представлены в табл. 1, а кривая $d-$ для четырехслойной, параметры которой представлены в табл. 2. В таблицах приведены характеристики легирования слоев (уровень легирования понимается как „,++“ $->10^{19},{ }^{\prime \prime}+{ }^{“ 6}-\sim 10^{19}$, 


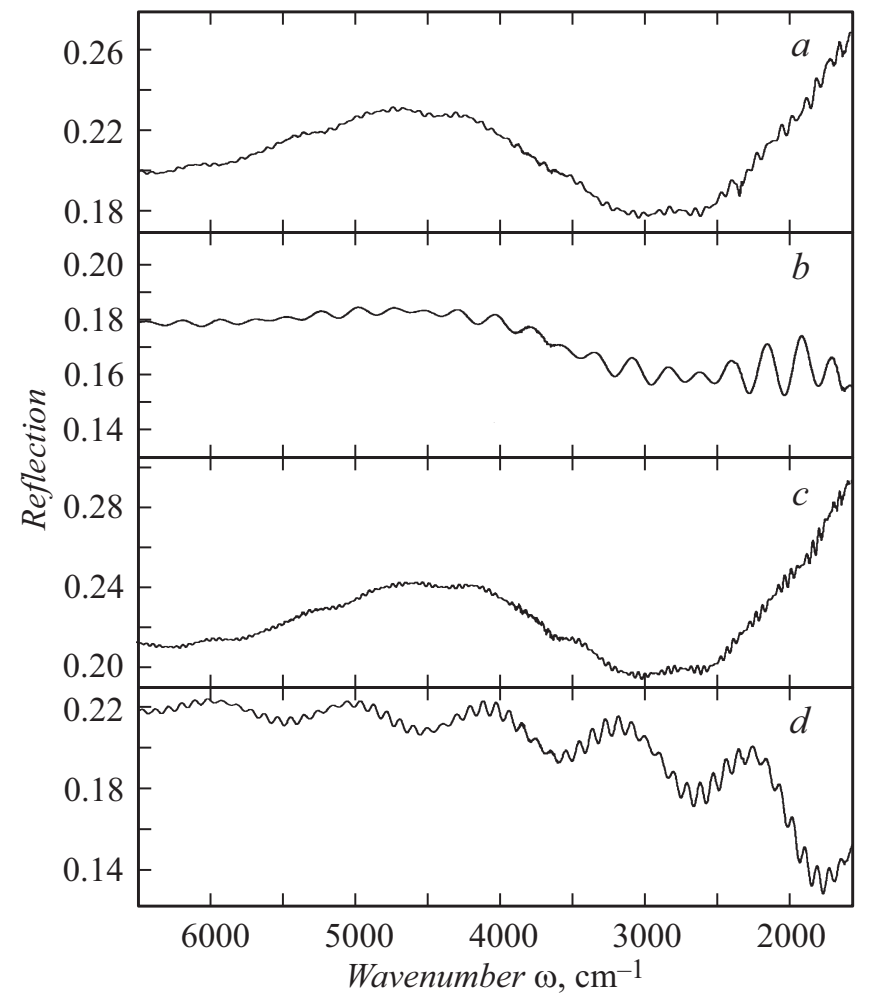

Рис. 5. Экспериментальные спектры отражения структур 1 4 (кривые $a-d)$.

Таблица 1. Легирование и толщина слоев трехслойных структур

\begin{tabular}{l|c|c|c}
\hline \multicolumn{1}{c|}{ Структура } & Слой 1 & Слой 2 & Слой 3 \\
\hline Легирование & $n^{+}$ & $p^{-}$ & $p^{+}$ \\
Запрограммированная & 10 & 16 & 5 \\
толщина, $\mu \mathrm{m}$ & 10.3 & 15.9 & 5.1 \\
Измеренная толщина, $\mu \mathrm{m}$ & $n^{+}$ & $\mathrm{p}$ & $p^{++}$ \\
\hline Легирование & 1.9 & 5.0 & 0.5 \\
Запрограммированная & 2.0 & 5.5 & 0.5 \\
толщина, $\mu \mathrm{m}$ & $n^{+}$ & $p^{-}$ & $p^{+}$ \\
Измеренная толщина, $\mu \mathrm{m}$ & 10 & 30 & 5 \\
\hline Легирование & 10.1 & 30.5 & 5.0 \\
Запрограммированная & & & \\
толщина, $\mu \mathrm{m}$ & Измеренная толщина, $\mu \mathrm{m}$ & &
\end{tabular}

„-“ $-<10^{17}$, остальные $\left.-10^{17}-10^{18} \mathrm{~cm}^{-3}\right)$. Там же приведены запрограммированные технологические толщины и определенные в настоящей работе значения толщин слоев. В табл. 1 представлены экспериментальные данные для трехслойных структур, полученные методом частотного анализа спектра. Для четырехслойной структуры представлены результаты, полученные методом частотного анализа (рис. 6, табл. 2) спектра, а также данные растровой электронной микроскопии, полученные путем исследования снимка полированного торца (рис. 7). (Номера слоев начинаются от подложки.)

Погрешность определения толщин, представленных в табл. 1 и 2, мы оцениваем следующим образом. Фундаментальная (минимальная) частота фурьепреобразования спектра, имеющая в нашей ситуации размерность длины, вычисляется с помощью формулы (1) как минимальная толщина, которую можно зафиксировать с помощью представленного участка спектра. Она соответствует максимальному периоду спектральной интерференции, укладывающемуся в диапазон наших измерений $-1500-6500 \mathrm{~cm}^{-1}$. Эта толщина равна $0.38 \mu \mathrm{m}$. Измерения спектра, полученные в различных точках эпитаксиальных структур, не дают изменений в результаты определения толщин. Следовательно, разброс толщин по площади уступает по величине минимальной толщине. Так что величину $\approx 0.4 \mu \mathrm{m}$ можно рассматривать как цену деления „измерительного прибора“", а погрешность определить как $\pm 0.2 \mu \mathrm{m}$.

В методическом плане определение толщин трех слоев одной структуры совпадает с процедурой соответствующего анализа теоретического спектра двухслойной (рис. 3, нижняя вставка): напрямую проявляется только гармоника, связанная с верхним слоем, и как разности определяются толщины, связанные с другими гармониками.

Частотный анализ кривой спектра отражения четырехслойной структуры (рис. 6) указал на наличие тонкого слоя на поверхности, который не был отмечен технологами. Непосредственная проверка химически полированного скола участка структуры путем исследования фотографии, сделанной методом РЭМ (рис. 7), показала наличие такого подслоя. В соответствии с этим слой 4 указан в табл. 2 как двухслойная композиция. Учитывая сверхвысокое легирование верхнего (контактного) слоя, его неоднородность можно связать с такой особенностью технологического процесса, как постадийный выход на высокую концентрацию примеси. В этом случае возможно образование двух подслоев с различной концентрацией носителей, создающее оптическую границу.

Результаты численного и реального экспериментов на примере эпитаксиальных структур карбида кремния (политип 4Н) показали возможность определения тол-

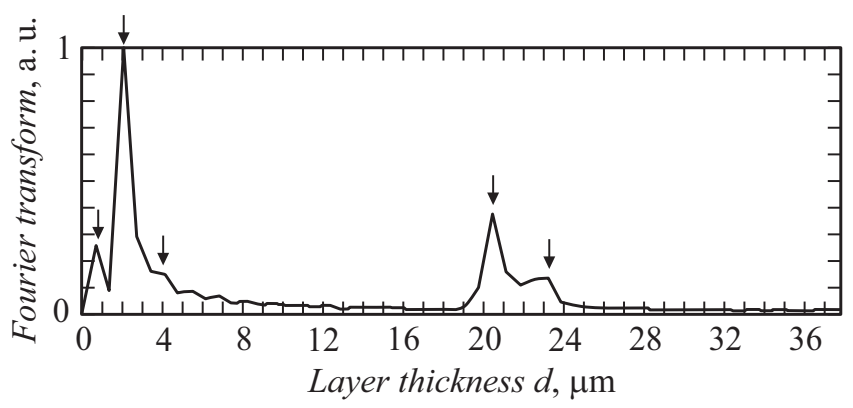

Рис. 6. Определение толщин четырехслойной структуры методом частотного анализа спектральной кривой отражения. 
Таблица 2. Легирование и толщина слоев четырехслойной структуры

\begin{tabular}{|c|c|c|c|c|c|}
\hline \multicolumn{2}{|c|}{ Структура } & Слой 1 & Слой 2 & Слой 3 & Слой 4 \\
\hline \multicolumn{2}{|l|}{ Легирование } & $p^{+}$ & $p^{-}$ & $n^{-}$ & $n^{+}$ \\
\hline \multicolumn{2}{|c|}{ Запрограммированная толщина, $\mu \mathrm{m}$} & 2.3 & 15.0 & 2.0 & 2.0 \\
\hline \multirow{2}{*}{ Измеренная толщина, $\mu \mathrm{m}$} & Частотный анализ спектра & 2.7 & 16.4 & 2.0 & $0.9+1.1$ \\
\hline & РЭМ & 2.6 & 16.4 & 1.8 & $0.8+0.8$ \\
\hline
\end{tabular}

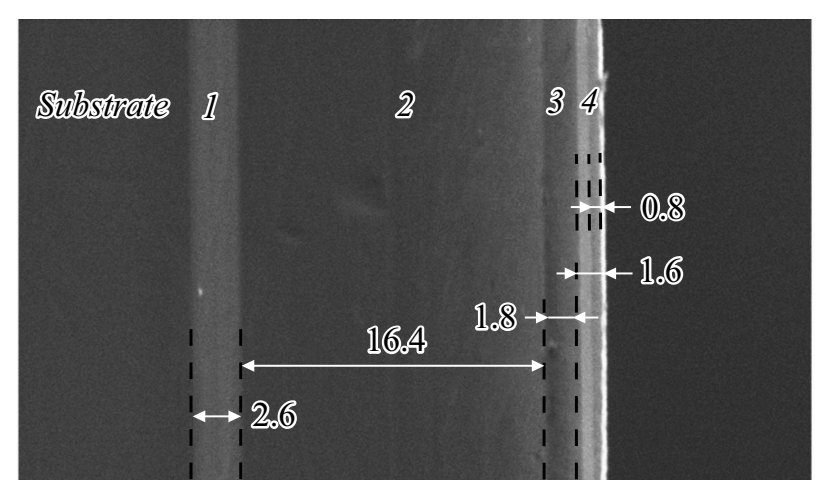

Pис. 7. РЭМ (микроскоп Quanta Inspect) снимок скола четырехслойной структуры.

щин многослойной структуры на основе слоев одного прозрачного кристаллического материала, отличающихся концентрацией легирующей примеси, с помощью спектрального анализа кривой отражения, полученной с помощью стандартного ИК фурье-спектрометра. Толщины, кроме верхнего слоя, соответствуют разностям найденных спектральных компонент. Разница измеренных значений толщин, а также их соответствующих технологических значений и данных, полученных с помощью РЭМ фотографий скола, в среднем не превышает единиц процентов. Чувствительность методики позволяет также фиксировать технологически не задокументированные слои.

\section{Конфликт интересов}

Авторы заявляют, что у них нет конфликта интересов.

\section{Список литературы}

[1] В.В. Лучинин Отечественная экстремальная ЭКБ: карбидокремниевая индустрия СПбГЭТУ „ЛЭТИ“. Наноиндустрия, 3 (65), 78 (2016).

[2] В.В. Лучинин Отечественная экстремальная ЭКБ: карбидокремниевая индустрия СПбГЭТУ „ЛЭТИ“. Наноиндустрия, 4 (66), 40 (2016).

[3] S. Oishi, Y. Hijikata, H. Yaguchi, S. Yoshida. Jpn Society Appl. Phys., 45-46, p. L1226 (2006).

[4] L. Zhi-Yun, S. Ji-Wei, Z. Yu-Ming, et al. Chinese Phys. Lett., 27 (6), 068103(2010).
[5] D. Lin, S. Guo-Sheng, Z. Liu, et al. Chinese Phys. B, 21 (4), 047802 (2012).

[6] L. Dong, G. Sun, L. Zheng, et al. J. Phys. D: Appl. Phys., 45, 245102 (2012).

[7] Ю.И. Уханов. Оптические свойства полупроводников (Наука, М., 1977)

[8] А.В. Марков, М.Ф. Панов, В.П. Растегаев, Е.Н. Севостьянов, В.В. Трушлякова. ЖТФ, 89 (12), 1869 (2019).

[9] Handbook of optical constants of solids, ed. E.D. Palik. (Academic, San Diego, 1998), p. 999.

[10] М.Ф. Панов, В.П. Растегаев, С.А. Корлякова. ЖТФ, 84 (8), 151 (2014).

[11] В.В. Батавин, Ю.А. Концевой, Ю.В. Федорович. Измерение параметров полупроводниковых материалов $u$ структур (Радио и связь, М., 1985), 264 с.

[12] K. Narita, Y. Hijikata, H. Yaguchi, et. al. Jpn. J. Appl. Phys. A, 43 (8), 5151(2004).

[13] М.Ф. Панов, Ф.Е. Рыбка, В.П. Растегаев. Определение кинетических параметров носителей в карбидокремниевых структурах методом моделирования спектров ИК отражения-V междисциплинарный научный борум с межсдународным участием Новые материалы и перспективные технологии“ (Сборник материалов, М., 2019), т. 1, с. 377 . (http://n-materials.ru/wp-content/uploads /2019 /12/2019- \%D0\%A2\%D0\%9E\%D0\%9C-1.pdf) 